\title{
Design de jogo multimídia: projeto fundamentado em relações filosóficas
}

\author{
Multimedia game design: project based upon philosophic relationships
}

\author{
David L. Desidério, Dorival C. Rossi
}

design, jogo, multimídia, filosofia, virtual

\begin{abstract}
Este artigo apresenta um estudo do processo de design de um jogo multimídia, baseado na teoria de game design como técnica, bem como em relações filosóficas como conteúdo. Procurou-se com este trabalho, discutir e buscar outra interpretação para ampliar a compreensão das noções de Design, de Multimídia e Jogo.
\end{abstract}

Design, Game, Multimedia, philosophy, virtual

This paper presents a study of the design process of a multimedia game, based on the game design theory as technique, as well as on philosophical relationships as contents. The aim of this work was to discuss and search for another interpretation in order to widen the notions of Design, Multimedia and Game.

\section{Introdução}

A história dos jogos remonta à própria história da humanidade. Há registros de que os antigos Egípcios jogavam "Senet", um jogo datado de 3.400 anos (EFE, 2006), parecido com o "gamão" e com "jogos de corrida" que possuía tabuleiro e peças. Johan Huizinga em 1938 propôs a denominação de "Homo Ludens" ao homem jogador, cuja história cultural remonta aos povos primitivos, chegando a propor que o jogo é anterior à própria cultura (Huizinga, 2000:3).

Huizinga (2000) define o jogo e o ato de jogar como uma atividade voluntária, limitada no espaçotempo, com regras consentidas livremente, porém obrigatórias, com uma finalidade em si, que acompanha sentimentos de tensão e alegria com uma consciência de que o ato é diferente da vida diária.

Sendo parte ou elemento da cultura desde os tempos da Antiguidade, o jogo nunca deixou de ter sua importância cultural ao longo dos tempos, e contemporaneamente os jogos digitais, eletrônicos e multimídias continuam integrantes constituintes da cultura.

Atualmente, de acordo com Thompson (2007:18-30), existem cinco gêneros principais de jogos digitais: "Shoot-'em-ups": atire em tudo (jogo de naves espaciais). "First-person shooter": atirador em primeira pessoa (mate ou morra). "Platform games": jogos de plataforma (corra contra o tempo, pule e colecione itens). "Strategy games": jogos de estratégia (estratégia em tempo real - Real time Strategy - RTS). "Puzzle games": jogos quebra-cabeça (jogos de raciocínio, carteado ou labirintos).

O jogo apresentado neste trabalho conjuga em si dois gêneros, ou seja, é um "jogo quebracabeça" em "primeira pessoa". Porém, o jogo descrito não envolve tiros e mortes ou a tão debatida questão da violência nos jogos eletrônicos (Thompson, 2007:23; Arbex \& Tognoli, 1996:46-50; Greenfield, 1988:89-92). A maior parte dos jogos, já tem repetido de forma exaustiva o contexto básico da dualidade humana "o bem contra o mal", ou "matar para não ser morto", explorando de uma forma visceral o instinto de conservação que existe desde os mais primitivos animais. A parte mais instintiva do animal no ser humano é estimulada quando são jogados estes jogos. Os jogos de estratégia que lidam com a administração de recursos ou os jogos quebra-cabeças são os únicos gêneros nos quais se estimula, na maior parte das vezes, o componente racional e intelectual do ser humano.

Filosoficamente, Johan Huizinga (2000:6) considera que a "realidade do jogo ultrapassa a esfera da vida humana", e que "reconhecer o jogo é, forçosamente, reconhecer o espírito, pois o jogo, seja qual for sua essência, não é material". Pode-se inferir por estas assertivas que o jogo remete ou deveria remeter a algo transcendente ou metafísico. O jogo em si já transcende essas 
características dualísticas de conceitos meramente humanos como bem e mal, sabedoria e loucura, verdade e falsidade, vício e virtude, apontando não mais para um ser humano, mas para um ser espiritual transcendente às dualidades ou antíteses. Acerca disso o autor questiona: "Se, portanto, não for possível ao jogo referir-se diretamente à categoria do bem ou da verdade, não poderia ele talvez ser incluído no domínio da estética?" (Huizinga, 2000:9).

A proposta do jogo descrito neste artigo é de se aproximar da questão estética enquanto dimensão transcendente espiritual, e aí já se pode visualizar uma ampliação do conceito de jogo. Utilizando-se de formas geométricas projetadas em uma retícula quadriculada para se construir um labirinto confuso e desafiador, nota-se a característica estética da criação em Design deste jogo digital. Foi concebido com formas curvas e circulares, pois inicialmente foram tomados como referência para criação, os Círculos Ingleses (Lundberg, s/d), as Mandalas (Kumar, 2000) e os Labirintos.

Não somente em seu aspecto gráfico, mas em todo o conceito norteador do design do jogo, procurou-se abranger um caráter mais amplo da noção de Design como sendo transdisciplinar, ou seja, relacionando entre si, várias áreas do conhecimento como a Arte, a Filosofia, a Ciência, a Tecnologia, entre outros e conhecimentos Transcendentes ou metafísicos no projeto do jogo.

\section{O jogo "Virtualidade Trans-Sensorial"}

Fundamentado em relações entre variados conhecimentos, desenvolveu-se o jogo "Virtualidade Trans-Sensorial". Para explicar o nome do jogo, fez-se uma analogia com a palavra "Realidade Virtual", porém em outra conotação. "Virtualidade" neste caso significaria a própria constituição da Transcendência, que já é por si, inapreensível aos órgãos dos sentidos, e envolve outros tipos de percepção extrassensorial. Por isso "Virtualidade Trans-Sensorial". O jogo é mais uma das virtualidades da Transcendência que escapam aos sentidos físicos. A sua compreensão, enquanto conceito requer transcender os receptores sensórios e a mentalidade materialista impregnada e condicionada à realidade manifesta, ou seja, esforçar-se para sentir algo além dos cinco sentidos conhecidos. Até mesmo a linguagem torna-se insuficiente para a compreensão e abrangência da profundidade de tais conceitos.

A relação entre a Transcendência e o Virtual, pode ser justificada e compreendida conforme alguns postulados da Física Quântica comparados à filosofia do Virtual. Amit Goswami (1998) explica que de acordo com o modelo atômico de Niels Bohr, prêmio Nobel de Física em 1922, o elétron em um átomo "pula" de uma órbita para a outra sem percorrer o espaço entre as camadas dos orbitais (Goswami, 1998:50-52). Quando o elétron recebe uma carga de energia, ele desaparece da camada onde está e reaparece numa camada mais afastada do núcleo, que comporta um quantum maior de energia para este elétron (dá um salto quântico). $\mathrm{E}$ o contrário também se processa quando o elétron volta para sua carga energética natural, mas na volta este elétron liberará um fóton, ou seja, uma partícula luminosa. A explicação para este fenômeno está na própria natureza da matéria explicada por Louis De Broglie, que postulou a teoria das "ondas de matéria" em que todas as partículas materiais podem ser observadas tanto como ondas quanto como partículas. Ou seja, quando a Consciência não está observando, as partículas tornam-se ondas e espalham-se de acordo com uma equação descoberta por Erwin Schrödinger, contudo não o fazem neste espaço tridimensional e sim em um "domínio transcendente da realidade", chamado por Heisenberg, de potentia (Goswami, 1998:83-84; Heisenberg, 1958:53).

Para von Neumann citado por Goswami, (2003:31-32) a Consciência causa um colapso na função de onda e as interpreta como matéria, por conseguinte, a Consciência deve ser transcendente à realidade material (Goswami, 1998:124-126). A realidade material é apenas uma ilusão dos sentidos; que em si mesma não é sólida, conforme inferências relativas ao desenvolvimento da Física Quântica (Arntz, 2007).

Sobre o conceito de Virtual, Pierre Lévy (1996) refere que: "A palavra virtual vem do latim medieval virtualis, derivado por sua vez de virtus, força, potência. Na filosofia escolástica, é virtual o que existe em potência e não em ato. (...) O virtual, com muita frequência, 'não está presente' (nesta realidade)". Também ressalta que o "virtual não se opõe ao real, mas sim ao atual" (Lévy, 1996:15-19). Neste caso, nada impede que o Virtual esteja intimamente ligado ao "Real Absoluto" das Filosofias Orientais e ao "domínio transcendente da potência" da Física Quântica. E ainda Lévy relaciona o "dualismo da substância e do acontecimento", que são dois pólos do 
latente,ao"yin" e "yang" da filosofia chinesa, também utilizado por Niels Bohr em seu brasão, como analogia ao "princípio da complementaridade", bem como a dualidade onda-partícula da Física Quântica (Lévy, 1996:144).

Essas idéias relacionadas sugerem que o Virtual é "O Real", que é o mesmo que uma dimensão Transcendente, formada por ondas de probabilidades que ao nível do possível podem vir a ser "coisas" que podem ser compreendidas como "não-coisas", na medida em que sendo virtuais, apenas não possuem uma manifestação no espaçotempo, não significando que sua existência seja negada. Podemos chamá-las de idéias ou conceitos que se encontrariam em uma "não-localidade" (Arntz, 2007:59; Goswami, 1998:41), análoga ao mundo das idéias de Platão ou à "sincronicidade" de Carl Gustav Jung (Goswami, 1998:159-160).

A importância disto para o Design é que o processo de criação tem suas bases na criação da própria realidade do mundo material por parte de Consciências co-criadoras, como coloca Goswami (1998). O designer deve ser por meio do insight criador, consciente do que faz, consciente de que cria a sua realidade e a de muitas outras Consciências que ainda se encontram inconscientes disso. O insight é o salto quântico da mente e o designer deve dar materialidade e existência a insights e conceitos transcendentes e abstratos, que são virtuais e potenciais, contudo, reais. A proposta do jogo "Virtualidade Trans-Sensorial" é colocar todas estas questões filosóficas e muitas outras no projeto de design de jogo multimídia, como pressupostos criativos, sendo inseridos implicitamente, porém conscientemente.

Design de jogos é o nome que se dá à atividade de se projetar jogos, mais comumente utilizada no projeto de videojogos eletrônicos ou jogos digitais multimídia. O design se encontra na relação que é estabelecida entre o jogador e o jogo, ou seja, na interface entre o homem e a máquina como intermediadora das relações, bem como na pesquisa, nos estudos e relações entre os conceitos norteadores envolvidos na construção do próprio jogo. Estes jogos são audiovisuais e interativos, em que uma ação do usuário causa uma reação no sistema e o sistema por sua vez, "responde" ao usuário ou jogador, através de outro estímulo auditivo e/ou visual. No jogo também é importante a questão da dificuldade em se alcançar o objetivo, pois sem isso, não há jogo. São essas características que constituem basicamente um videojogo eletrônico (ou jogo), comumente chamado de videogame ou simplesmente game.

\section{Reflexões filosóficas como referência projetual: labirintos (mazes); dobras e redobras; atomismo grego; a ilusão de maya e o deus Shiva}

Os desenhos e reentrâncias, os designs e layouts dos Círculos Ingleses (figura 1) e das mandalas (figura2), serviram como base para a criação de um labirinto ("maze") ${ }^{1}$. Com frequência o termo "labirinto" é utilizado como metáfora para uma situação difícil, confusa e obscura. De acordo com Kern (2000:23), este significado já era usado desde o Século 3 d.C. e remete ao conceito de "maze", que é "uma estrutura tortuosa que oferece ao caminhante muitos caminhos, alguns dos quais levam a becos sem saída" (Kern, 2000:23). Contudo, o termo "labirinto" pode significar também uma figura gráfica linear, que possui uma forma circular ou retangular, mais bem definida, fazendo sentido quando vista do topo, como a planta de uma construção, na qual as linhas são as paredes e os espaços são o caminho a ser percorrido (Kern, 2000:23). O autor relata que no design do labirinto original, o "caminho começa com uma pequena abertura no perímetro e leva ao centro dirigindo-se de forma circular por todo o labirinto" (figura 3). Diferentemente de um "maze", em um verdadeiro labirinto, o caminho circular único não é intersectado por outros, pois este leva invariavelmente ao centro (Kern, 2000:23).

\footnotetext{
${ }^{1}$ Em Inglês, o termo 'labyrinth' é diferente do termo 'maze' (lê-se, 'meize'), contudo, em Português, a tradução 'labirinto' é a mesma para os dois termos. Quando for encont rada a palav ra 'I abirinto' esta se refe rirá a o te rmo 'labyrinth', e nquanto 'maze' permanecerá sem tradução.
} 


\section{Infodesıgn}

Figura 1: Círculos desenhados em plantações inglesas
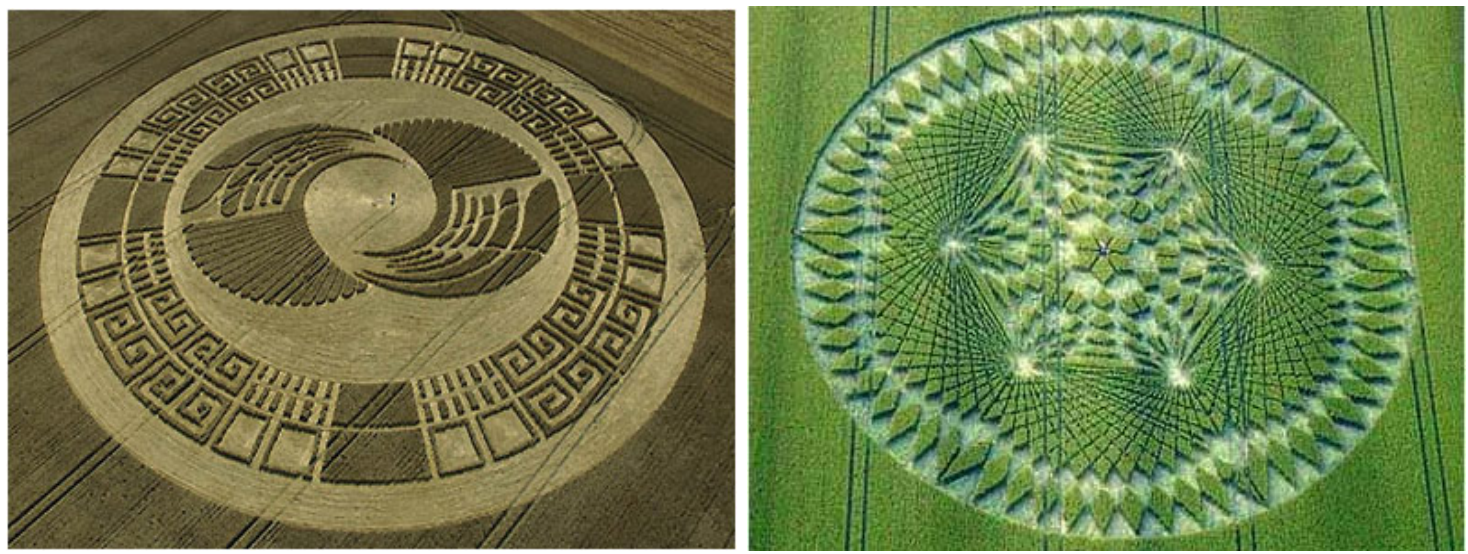

Figura 2: Configuração e design das mandalas.
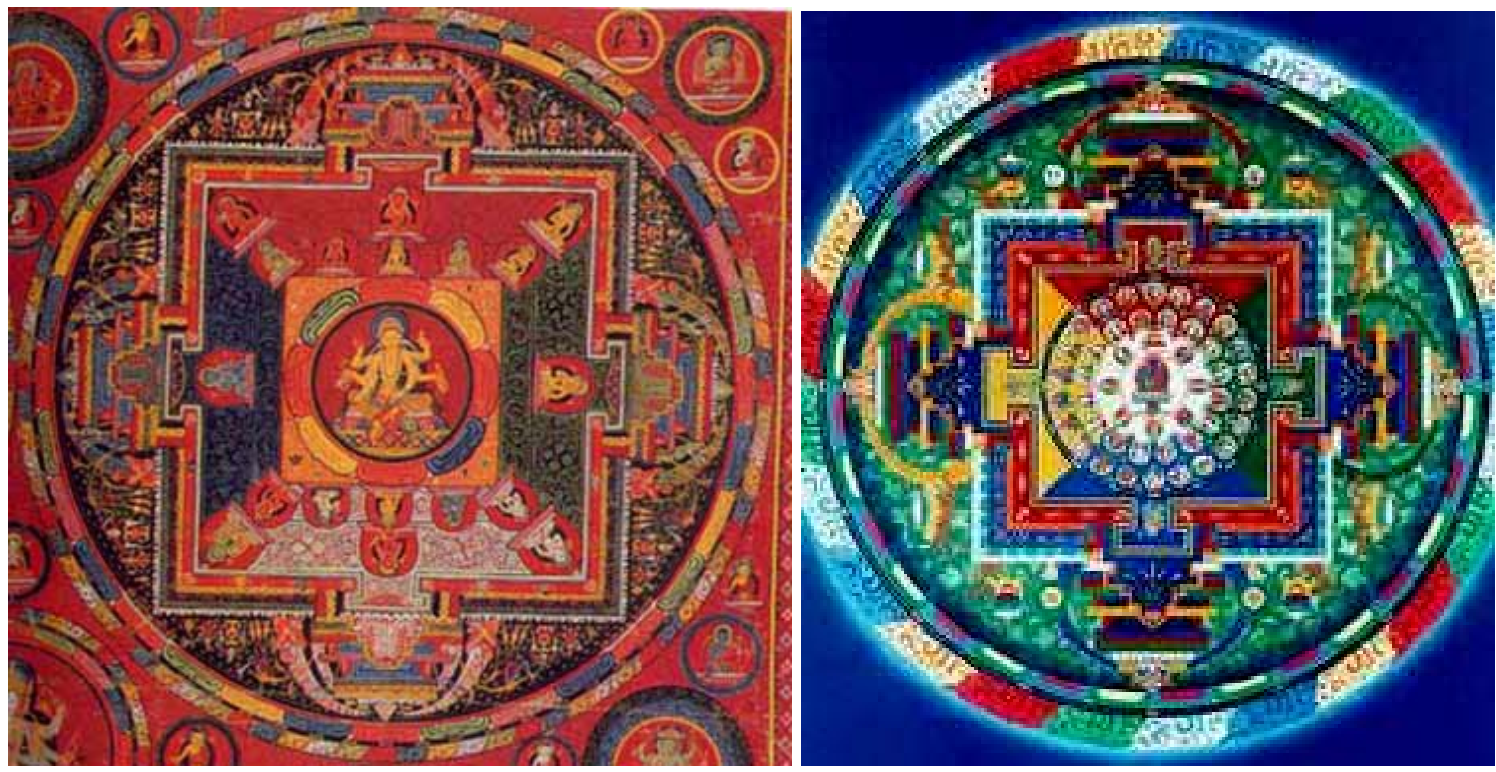

Figura 3: Labirinto original à esquerda e maze à direita
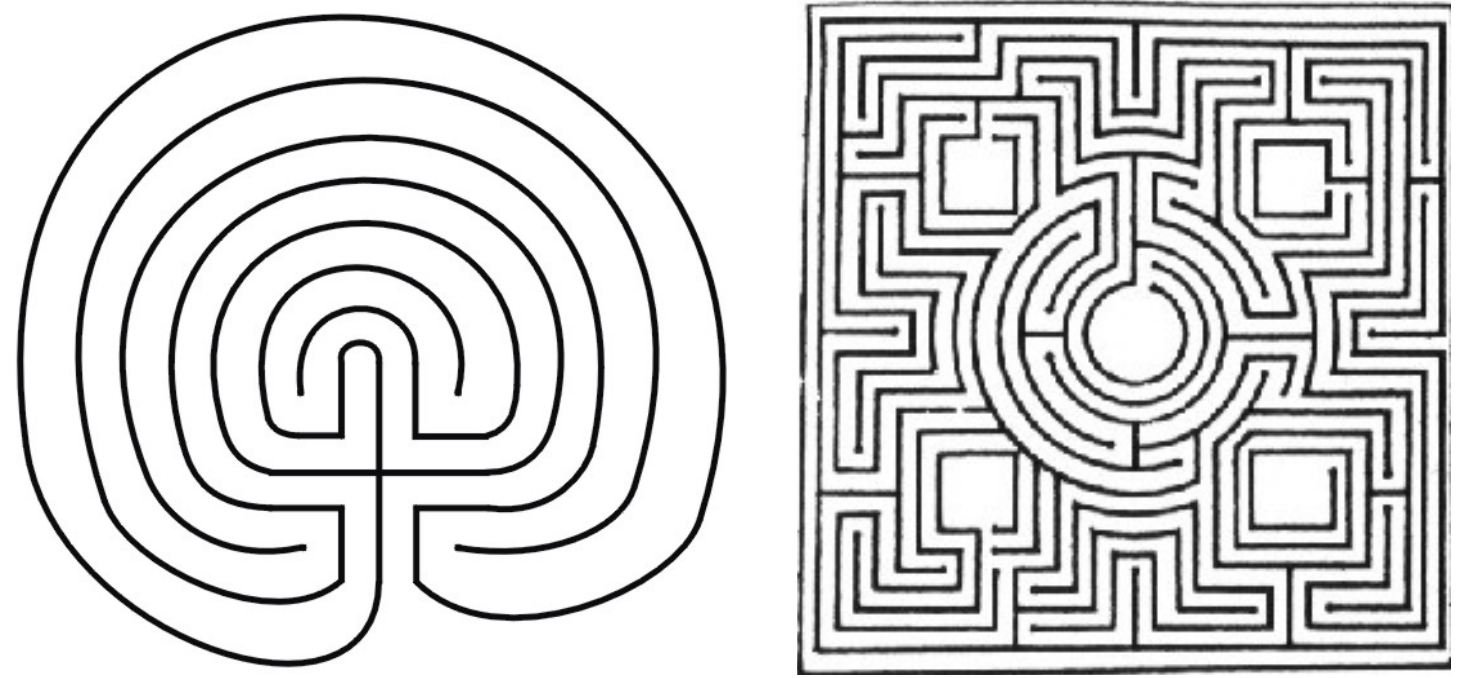

InfoDesign Revista Brasileira de Design da Informação 6 - 1 [2009] 36-45 
Assim como as mandalas, os labirintos (no sentido de "maze") são todos compostos por dobras que podem ser tanto curvas como retas dobradas. O filósofo Gilles Deleuze (1991) argumenta que os labirintos são múltiplos, pois possuem muitas dobras, e que existem dois andares labirínticos: "o labirinto do contínuo, na matéria e em suas partes, e o labirinto da liberdade, na alma e em seus predicados". E continua dizendo que esses andares se comunicam, sendo que no andar de baixo existem almas "envolvidas pelas redobras da matéria", e almas no andar de cima que ascenderam ${ }^{2}$. O filósofo cita Leibiniz ao dizer que há uma correspondência entre os dois andares labirínticos, "entre as redobras da matéria e as dobras na alma" (Deleuze, 1991). O autor ainda considera as veias do mármore como analogia das redobras da matéria e das dobras da alma (Deleuze, 1991), e que podem remeter à estátua em potência em um bloco de mármore esculpido por artistas gregos e às causas Aristotélicas (material, formal, eficiente e final) descritas por Lévy (1996:138).

Os gregos construíram as bases do conhecimento ocidental por meio de reflexões filosóficas lógicas. Zenon de Eléia (aproximadamente 504 a.C.) e Empédocles (século V a.C. 490 a 430 a.C.) pertenciam à escola dos Eleatas. Empédocles propôs que tudo no Universo seria composto por quatro elementos: a água, o ar, a terra, e o fogo (Andrade, 2001:27). Zenon parece ter sido um dos mestres de Leucipo, a quem é atribuída a criação do atomismo grego, posteriormente desenvolvida por Demócrito, seu discípulo. Leucipo de Mileto viveu aproximadamente de 500-430 a.C. Já Demócrito de Abdera (460-370 a.C.) ajudou-o a desenvolver suas idéias. É importante ressaltar que foi Leucipo quem concebeu os "pedaços indivisíveis de matéria" e foi Demócrito quem os nomeou de "átomos" (que significa "não-cortável"), e declarou que "a alma se constitui de átomos esféricos", segundo Aristóteles (Andrade, 2001:94). No século IV a.C., Aristóteles (384-322 a.C.) acrescentou um quinto elemento, o éter, à teoria dos elementos de Empédocles. $O$ éter seria a matéria constitutiva dos corpos celestes, (o sol, a lua, as estrelas e planetas). Platão (428-347 a.C.) combinou vários conhecimentos dos seus contemporâneos para desenvolver o atomismo grego, unindo o descobrimento dos sólidos regulares dos Pitagóricos, aos elementos de Empédocles. Também comparou "as menores partes do elemento terra com o cubo, do ar com o octaedro, do fogo com o tetraedro, e da água com o icosaedro" (Heisenberg, 1958:68), para compor a criação do mundo (figura 4).

Figura 4: Átomos da matéria segundo os gregos: Terra, ar, fogo, água e alma.

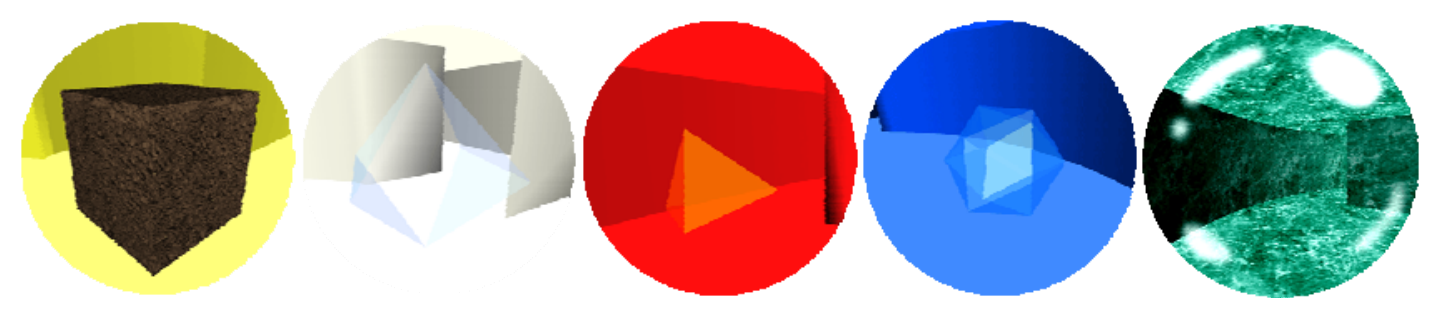

Na mitologia Hindu a criação do mundo se dá pelo auto-sacrifício de Deus. Sacrifício, no sentido de "fazer o sagrado", o sacro ofício, no qual Deus se torna o mundo e, depois, o mundo torna-se Deus novamente. Essa criação é chamada de "lila" a peça divina, cujo palco é o mundo. Como no teatro, há componentes que se reúnem para cumprir suas funções e desempenhar seus papéis. Mas estes geralmente se encantam pelas funções e esquecem-se de que o teatro do mundo é apenas um palco temporário.

A ilusão reside meramente em nosso ponto de vista, se pensarmos que as formas e estruturas, coisas e fatos existentes em torno de nós são realidades da natureza, em vez de percebermos que são apenas conceitos oriundos de nossas mentes voltadas para a medição e a categorização. Maya é a ilusão de tomar tais conceitos pela realidade, de confundir o mapa com o território (Capra, 1999:73).

As mandalas tibetanas possuem em seu centro uma divindade à qual está relacionada. $A$ mandala em forma de maze do jogo "Virtualidade Trans-Sensorial", tem o deus Shiva (uma divindade Hindu) relacionada ao seu centro. É "um dos mais antigos deuses indianos e pode assumir muitas formas. (...) Sua aparição mais celebrada corresponde a Nataraja, o Rei dos Dançarinos." (Capra, 1999:74, 183-184).

\footnotetext{
${ }^{2} \mathrm{O}$ andar de baixo de Deleuze (1991) poderia ser interpretado como nosso mundo físico, pois somos almas temporariamente 'envolvidas' pela matéria física, enquanto que o andar de cima poderia ser interpretado como um domínio existencial transcendente, no qual as almas já estariam libertas da matéria, de uma forma mais consciente.
} 


\section{Relações dos pressupostos filosóficos com o jogo "Virtualidade Trans-Sensorial"}

O jogo proposto neste trabalho constitui-se de dois estágios. O jogador deve percorrer o maze para chegar ao centro do "Andar de Baixo" para alcançar o segundo estágio, o "Andar de Cima". Pela natureza dos mazes torna-se complicado alcançar esse objetivo, porém não impossível.

O Primeiro Estágio é o "Andar de Baixo", um maze contínuo e linear, com o objetivo de se alcançar o centro, porém com caminhos confusos e ilusórios. Suas fases são baseadas no atomismo grego, compondo cinco fases com átomos da terra, do ar, do fogo, da água e da alma. Entre as fases, há "antessalas de decisão" onde o jogador abre ou fecha as portas que darão acesso às fases pelas quais ele precisa passar para chegar ao centro. Existe um conjunto de botões com seis esferas que vão mudando de cor ao mesmo tempo, fazendo com que as esferas sejam iguais, porém cada esfera ao ser clicada toca um som correspondente à porta de cada fase que se abre ou fecha: sons de terra, de ar, de fogo, e de água. Ao clicar nas esferas externas, pode ser que abra ou feche as portas das primeiras quatro fases, e clicando na esfera do centro, abrem-se as portas que dão acesso à Quinta Fase, e átomos aparecem indicando um caminho possível a ser seguido. As fases são baseadas também na idéia de maya que faz a fase parecer "real" pelas texturas, mas possuem "algo" de ilusório, sendo iluminadas com as cores utilizadas nas mandalas (figura 5).

Figura 5: Maze do jogo "Virtualidade Trans-Sensorial". Design criado por Desidério (2003).

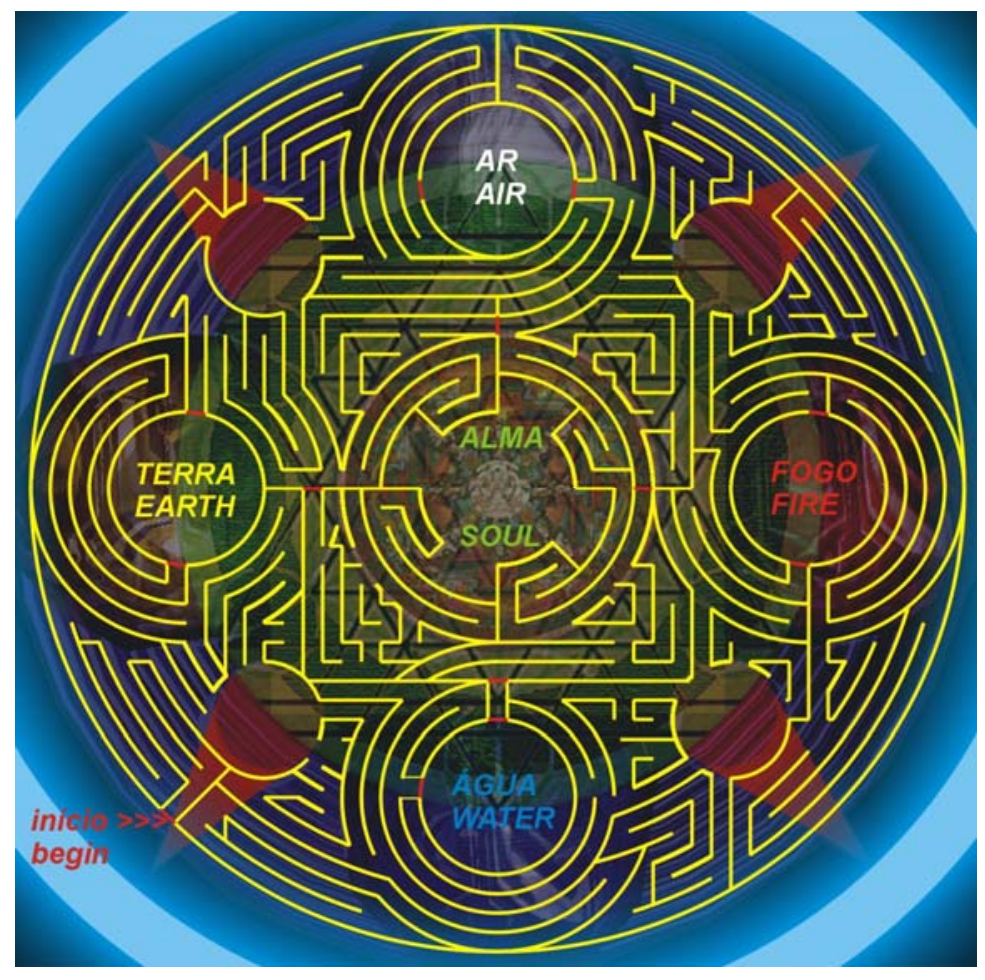

A Primeira Fase do Primeiro estágio é a "Terra Cúbica", onde é preciso desenterrar a porta e o cubo que a abre. Esta fase é composta por cubos com texturas de terra marrom e sons de terra sendo pisoteada ou jogada ao chão além de uma música parecida com um mantra tibetano em tom grave. Existem montes de cubos empilhados que o jogador pode arrastar como se estivesse desenterrando o botão que abrirá a porta de saída. De fato, o botão em forma de cubo com uma cor marrom mais intensa, está embaixo de montes de cubos, que devem ser movidos para que este botão seja encontrado. Também é preciso desbloquear a porta de saída para poder deixar desta fase que é iluminada com a cor amarela.

A Segunda Fase é o "Ar Octaédrico", na qual, para ser mais rápido que o vento é preciso apanhar $\mathrm{o}$ ar em movimento. É iluminada com a cor branca. Nesta fase com texturas de nuvens brancas o botão que abre a porta da saída é um octaedro mais escuro que se movimenta rapidamente por todos os lados. Porém existem muitos outros átomos de ar que vão se 
movimentando de um lado para o outro, confundindo o jogador. Deve-se acertar o clique no octaedro correto para poder abrir a porta. O sound design desta fase inclui sons de ventos fortes e ventanias com ventos uivantes, além de uma música em estilo indiano com vozes suaves dando uma sensação aérea.

A Terceira Fase é o "Fogo Tetraédrico", em que se queima para depois tocar o fogo. Esta fase cuja textura é de um subterrâneo de lavas, iluminada com a cor vermelha possui sons de fogo. No centro existe uma pira com átomos em forma de tetraedro. Cada átomo ao ser clicado toca um som de grito de dor, pois o jogador "está se queimando". O botão que abre a porta está escondido e somente clicando-se no átomo de fogo exato é que se consegue fazer aparecer o tetraedro que abrirá a porta. Este botão tem uma textura animada de fogo e quando é descoberto pelo jogador, aparece no centro e acima da pira. Os sons da fase dão uma sensação auditiva de alta temperatura influenciada principalmente pela trilha sonora na qual a cantora canta uma música forte, com voz gritante e vigorosa, porém ainda no estilo do oriente médio.

A Quarta Fase é a "Água Icosaédrica", onde é preciso se molhar para pegar a gota d'água. Nesta fase, entra-se numa sala com textura de um mar sem fim, onde há canos ao redor que despejam água em forma de grandes icosaedros. E quando o jogador entra, a sala começa a encher-se de água. O botão, com textura transparente, que abre a porta de saída começa a "pingar", ou seja, movimentar-se de cima para baixo e, se a sala encher-se totalmente, não se pode mais clicar no botão que abre a porta. Torna-se difícil encontrar a porta de saída debaixo da água, pois ela se torna desfocada pela influência da iluminação de cor azul da sala. Seus efeitos sonoros envolvem gotas pingando e sons de mergulho, com trilha sonora em estilo oriental indiano com um canto de voz trêmula que remete a um estado líquido e ondulatório.

A Quinta e última Fase do Primeiro Estágio, é a "Alma Esférica", onde se pode escolher, após encarar a multiplicidade, encontrar-se na Unidade ou perder-se na ilusão material. Na Quinta Fase, iluminada com a cor verde, o jogador alcançou o centro, podendo partir para o Segundo Estágio, que é o "Andar de Cima". Neste ponto, todas as interpretações metafísicas dos labirintos e das mandalas convergem. Inclusive as veias do mármore que compõem as redobras da matéria e as dobras na alma, pois as texturas que foram utilizadas nesta fase são de um mármore verde. Ao centro há uma imagem animada do deus hindu Shiva Nataraja dançando. Nesta última fase do maze, antes da ascensão ao "Andar de Cima", há a possibilidade de uma experimentação estética com texturas do deus Shiva dançando, que se subdividem fractalmente, formando múltiplas imagens diferentes. São as mais atraentes interatividades desta fase, que podem impedir que o jogador alcance o próximo estágio, por perder-se nas redobras da matéria marmoreada (figura 6).

Figura 6: Imagens das fases do "Andar de Baixo": Terra, ar, fogo, água e alma.
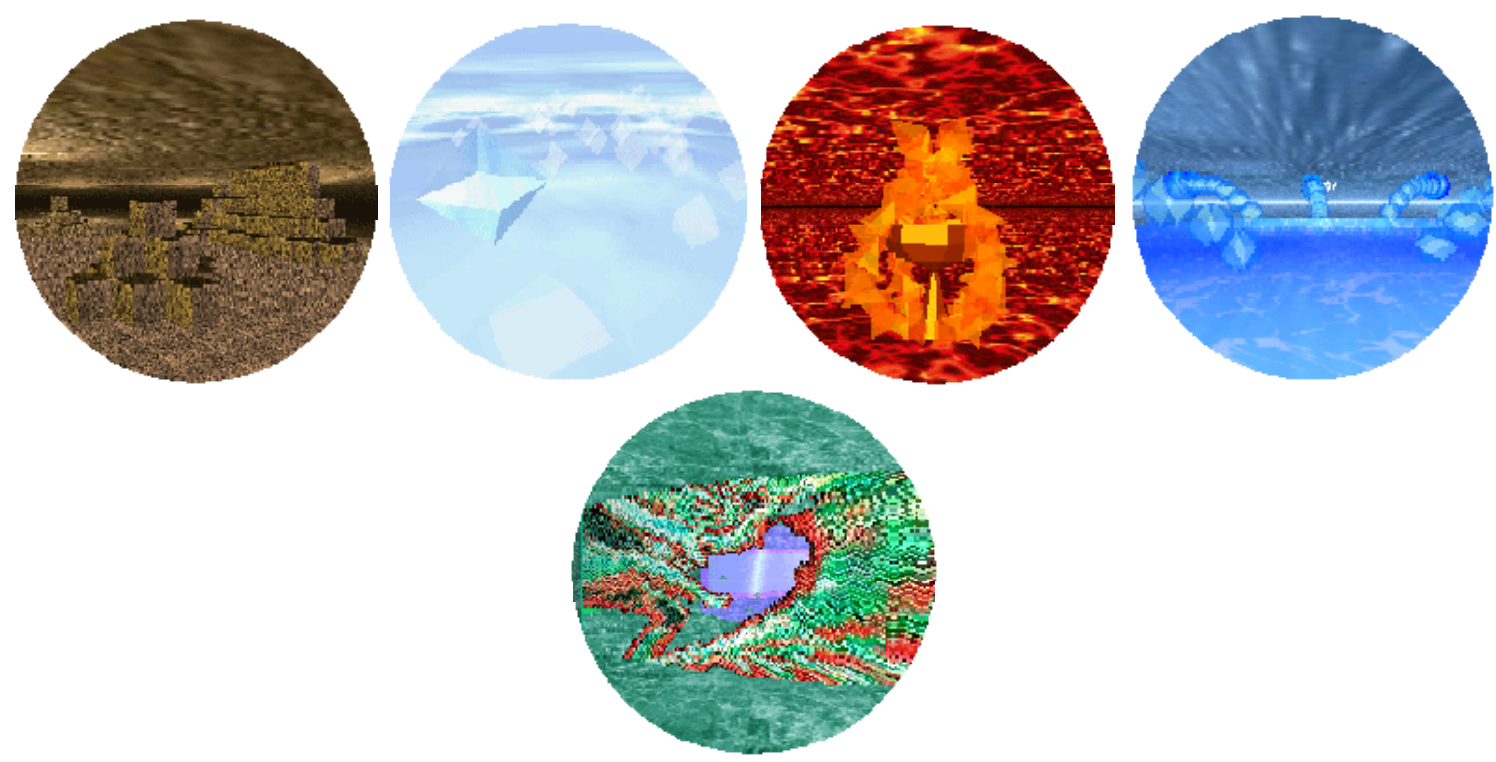

O "Andar de Cima", ou Segundo Estágio, não possui suas próprias fases, é um espaço de navegação livre onde o usuário não tem colisões com formas e imagens do ambiente e pode flutuar e percorrer todos os espaços, nos quais se tem uma fruição estética. Pode até ver o andar 
inferior, porém, não pode reentrar nele por fora depois que já se "libertou".

\section{Multimídia/multimeios}

A multimídia é definida como "a integração, controlada por computador, de textos, gráficos, desenhos, imagens paradas e em movimento (vídeo), animações, áudio e outras mídias, que possa representar, armazenar, transmitir e processar digitalmente todos os tipos de informações" (Marshall, 1999). A multimídia também pode agregar a si o componente interativo. Pinho e Kirner (1997) fazem uma comparação entre multimídia e realidade virtual quanto ao aspecto técnico, diferenciando estas duas tecnologias; contudo, Harper, Hedberg e Wright (2000), pontuam que a multimídia interativa e a "virtualidade" (realidade virtual) podem ter alguns atributos em comum.

"Meio" é uma posição que está exatamente entre dois extremos. Em comunicação sabe-se que "mídia" ou "meio" se refere ao modo como a informação é transmitida, ou seja, o "intermediário" que transporta informações. Se há muitos "meios" de transmissão de informação, há um sistema de comunicação "multimeios". Pode-se entender o "meio" como o "médium" entre um emissor e um receptor de informações. A comunicação se dá por este processo no qual ocorre uma relação entre Consciências conforme Martino (2002:23). "Meio" também pode se referir a um método para se alcançar um objetivo ou fim. Se todas essas noções forem compiladas, poder-se-á ampliar o conceito de "multimeios", interpretando-o conforme a proposta deste trabalho em conformidade com a noção mais ampla de Design enquanto transdisciplinaridade, ligando-o aos múltiplos meios para se alcançar um determinado fim. Se aceitar-se que as muitas áreas do conhecimento formam um todo único em se reunindo, mas com múltiplas manifestações, chega-se à conclusão de que estas formas de conhecer o mundo são apenas "meios", para se alcançar algo muito maior, como um conhecimento sistêmico e holístico do Universo e do Ser em si mesmo. Portanto pode-se notar que os caminhos para se chegar a este "Absoluto" são múltiplos, portanto, "multimeios" para um determinado fim que poderia ser alcançar uma dimensão ou estado de Consciência Transcendentes, nesta proposta ampliadora de conceitos.

\section{Considerações Finais}

Pode-se considerar que a produção de qualquer peça, objeto ou produto de design pode envolver os mais variados conceitos desde que estejam relacionados logicamente à proposta do projeto. No caso deste jogo, foram utilizados conceitos e reflexões que demonstrassem uma busca por algo "Maior", uma Transcendência, uma quebra de velhos conceitos e uma ampliação de Consciência, que pudesse abrir a mente para realidades "invisíveis", porém tão ou mais Reais do que a realidade ordinária; reflexões estas, que deveriam ser aventadas nos meios acadêmicos, mas que geralmente permanecem engolidas pela ilusória peça da realidade desta existência temporária e pela sensação de separatividade do mundo e de todos.

Nota-se atualmente, que a separatividade e a divisão em disciplinas não se justificam mais, por isso tem se propagado os conceitos de multi, inter e transdisciplinaridade (Nicolescu, 2001; D'ambrosio, 2001). Portanto, ainda há que se refletir e utilizar-e da Ciência, da Filosofia, da Religião, da Arte, da Metafísica, da Teologia, da Tecnologia e tantas outras formas de conhecimento, buscando traços de união entre si e ousar, propondo hipóteses de trabalho que podem às vezes, contrariar o que está estabelecido pela Ciência atual. É desta forma que o conhecimento avança.

Este trabalho propõe a idéia de que conforme as fundamentações teóricas, ou as reflexões filosóficas como informações codificadas em um projeto de design, que espelham na realidade a intenção comunicativa do designer com determinado projeto, pode-se contribuir para melhorar ou para piorar o seu ambiente interno (subjetivo), o ambiente externo (objetivo) e as outras subjetividades que entrarão em contato não somente com o projeto, mas com o processo e o produto, quando da relação entre os sujeitos e os objetos que compõem esta interação.

Todavia, esta interação toma uma dimensão totalmente nova em tempos atuais, pois comumente se considera a separação do sujeito e do objeto como condição essencial para o desenvolvimento dos métodos da Ciência, fato que já foi suplantado desde o advento da Mecânica Quântica. Estabeleceu-se que o objeto a ser observado interage diretamente com a consciência 
do sujeito observador a ponto de alterar os resultados das experimentações. Portanto, o paradoxo da individualidade ser uma indivisível dualidade, se resolve quando se compreende que não existem sujeito, nem objeto, nem dualidades na Unidade Transcendente.

É necessário ter coragem para mudar os métodos, encarar a irracionalidade das experiências e perceber os paralelos existentes entre a Ciência, a Religião, as Artes, a Filosofia etc. A humanidade caminha para a integração do conhecimento; é natural e inevitável. E o fator Virtual tem um papel decisivo neste processo de integração. Por meio do Virtual as "coisas" e as "não coisas" não se diferenciam mais. O Virtual é a Transcendência formada por miríades de virtualidades não convertidas em ato, além de possibilidades não realizadas. Sendo a Transcendência, a "Realidade Última" ou o "Real Absoluto" segundo as filosofias Orientais, tira-se daí que a Transcendência também é o Virtual na conotação de Real que é eterno, sem começo nem fim, e não manifesto. Pode-se chamar de Virtual qualquer realidade invisível, não manifesta, portanto transcendente. É dessa Transcendência, que tudo é originado, ou seja, atualizado ou criado; deste modo tudo deve existir virtualmente na Transcendência - e, com efeito, se o virtual existe, tanto a virtualização como a atualização são da ordem da criação. Pode-se inferir que estes são movimentos "divinos" e sabe-se que todos possuem essa capacidade criativa "divina" dentro de si, pois é o Espírito quem cria, mas o designer é treinado para utilizar-se da sua capacidade criadora inata, daí a importância da ampliação e transcendência de conceitos e de Consciência, da abertura da mente para sentir o invisível.

O Virtual é como o ponto imóvel, o ponto de convergência, o ponto de mutação, é onde tudo será, mas ainda não é, sendo; o Virtual pode ser um meio de transcendência porque é transcendente. O Virtual é tão Real quanto a própria dimensão Transcendente, e influencia diretamente o Design por meio da intuição, da inspiração e da criação, e consequente manifestação da idéia ou conceito invisíveis, na realidade visível. Essa concretização, atualização, realização ou colapso de ondas quânticas, depende da Consciência; essência espiritual de todos os Seres.

\section{Referências}

Andrade, H. G. 2001. PSI Quântico: Uma extensão dos conceitos quânticos e atômicos à idéia do Espírito. Votuporanga: Didier.

Arbex, J. \& Tognoli, C. J. 1996. Mundo Pós-Moderno. São Paulo: Scipione.

Arntz, W. 2007. Quem somos nós? A descoberta das infinitas possibilidades de alterar a realidade diária. Rio de Janeiro: Prestígio.

Capra, F. 1999. O Tao da física: um paralelo entre a física moderna e o misticismo oriental. São Paulo: Cultrix.

Cortona. 3D viewer. s/d. In: Parallel Graphics. <http://www.parallelgraphics.com/products/cortona>, 20/02/2009.

D’ambrosio, U. 2001. Transdisciplinaridade. São Paulo: Palas Athena.

Deleuze, G. 1991. A Dobra: Leibniz e o Barroco. Campinas: Papirus.

EFE. Agência EFE. 2006. Arqueólogos descobrem jogo de mesa egípcio de 3.400 anos. In: Terra Notícias. <http://noticias.terra.com.br/ciencia/interna/0,,OI950520-El1728,00Arqueologos+descobrem+jogo+de+mesa+egipcio+de+anos.html\#tab-photos>, 12/03/2009.

Goswami, A. 2003. A Janela Visionária: Um guia para a iluminação por um Físico Quântico. São Paulo: Cultrix.

Goswami, A. 1998. O universo autoconsciente: Como a consciência cria o mundo material. Rio de Janeiro: Rosa dos Tempos.

Greenfield, P. M. 1988. O desenvolvimento do raciocínio na era da eletrônica: Os efeitos da TV, computadores e videogames. São Paulo: Summus.

Harper, B.; Hedberg, J. G. \& Wright, R. 2000. Who benefits from virtuality? Computers \& Education, 34, pp.163-176. 


\section{Infodesıgn}

Heisenberg, W. 1958. Physics and Philosophy: The revolutions in modern Science. New York: Harper Torchbooks.

Huizinga, J. 2000. Homo Ludens: O jogo como elemento da cultura. São Paulo: Perspectiva.

Kern, H. 2000. Through the Labyrinth: Designs and meanings over 5,000 years. Munich: Prestel.

Kumar, N. 2000. The Mandala - Sacred Geometry and Art. In: Exotic India Art. <http://www.exoticindiaart.com/article/mandala>, 12/03/2009.

Lévy, P. 1996. O que é o Virtual? São Paulo: Editora 34.

Lundberg, J. s/d. Exhibit A. Seeing is believing. Top of the Crops. In: Circlemakers. <http://www.circlemakers.org/exhibit_a.html>, 20/02/2009.

Marshall, D. 1999. What is Multimedia? In: Multimidia. <http://www.cs.cf.ac.uk/Dave/MM/OLD_BSC/node10.html>,14/03/2009.

Martino, L. C. De qual comunicação estamos falando. In: Hohlfeldt, A.; Martino, L. C.; França, V. V. (org.). 2002. Teorias da Comunicação. Petrópolis: Vozes.

Nicolescu, B. 2001. O Manifesto da Transdisciplinaridade. São Paulo: Editora 34.

Pinho, M.S. \& Kirner, C. 1997. Uma Introdução à Realidade Virtual. In: Realidade Virtual e Aumentada. <http://www.ckirner.com/download/tutoriais/rv-sibgrapi97/tutrv.htm>, 12/03/2009.

Thompson, J. 2007. Game Design Course: principles, practice, and techniques - the ultimate guide for the aspiring game designer. Hoboken: Quarto.

\section{Sobre os autores}

David L. Desidério, Bacharel em Desenho Industrial, habilitação Programação Visual, Faculdade de Arquitetura, Artes e Comunicação - FAAC - Unesp, Bauru. Atualmente cursa o Programa de Pós Graduação em Design (Nível Mestrado). Tem experiência na área de Design, com ênfase em Programação Visual e Design da informação atuando principalmente nos seguintes temas: design, ilustração digital, realidade virtual, vrml e psicobiofísica.

<dldesiderio@yahoo.com.br>

Dorival C. Rossi, Doutor em Comunicação e Semiótica, Faculdade de Arquitetura, Artes e Comunicação - FAAC - Unesp, Bauru. Professor do curso de graduação e pós-graduação em Design Gráfico e Produto da Unesp Bauru. Desenvolve pesquisas em Novas Tecnologias e as interfaces líquidas entre ciência, arte e tecnologia (metaciência). Tem atividades nas áreas de design da informação e semiótica. Um dos criadores do grupo de pesquisas PIPOL na Unesp.

<bauruhaus@yahoo.com.br>. 